\title{
The role of 'social support' in the experience of fibromyalgia - narratives from South Africa
}

\author{
Silvie Cooper and Leah Gilbert
}

Department of Sociology, University of the Witwatersrand, Private Bag 3, Wits, 2050, Johannesburg, South Africa

\begin{abstract}
This paper focuses on the role of 'social support' in the experience of fibromyalgia (a musculoskeletal pain disorder) in South Africa. In-depth semi-structured interviews were used to collect narratives from 15 participants. Sources of social support constitute important mechanisms for coping with the illness experience of fibromyalgia. In providing a space for consultation and validation of the diagnosis of fibromyalgia, and the person living with the condition, people giving support fulfil a critical role in shaping the experience. The findings show how support from family, partners, and peers plays an integral role in the process of accepting fibromyalgia diagnosis, adapting to the demands of the condition, and seeking help from healthcare providers. The findings also show the ways in which people with fibromyalgia provide support for others with the condition, and the importance of this peer network in shaping the paths and outcomes of this illness experience. The findings of this study corroborate existing evidence that show fibromyalgia to be a complex condition to manage, due to the multiplicity, uncertainty and contestation that feature in the experience of the illness. Additionally, this study presents the challenges related to the limitations of access to healthcare in the South African context, and the utility of narrative approaches in garnering insight into the ways in which social support is harnessed in this environment.
\end{abstract}

\section{What is known about this topic}

- Fibromyalgia is a condition marked by uncertainty and contestation.

- In contexts where the diagnosis is still being established and is 'emerging' (such as South Africa), people with fibromyalgia are continuously required to prove the legitimacy of their diagnosis to healthcare providers and others.

- Social support constitutes an important part of addressing any health condition.

\section{What this paper adds}

- How peers, partners and family members either support or deride people with fibromyalgia.

- The particular role that people with fibromyalgia fulfil in providing support to others by dispensing advice and empathy for the experience.

- How this illness experience plays out in South Africa, which has an inequitable healthcare system.

\section{Introduction}

Fibromyalgia is a chronic musculoskeletal pain condition that is characterised by widespread pain, exhaustion, sleep disruption and myriad other symptoms that veer from the intangible to the concrete (Dennis et al. 2013). The condition has perpetually been classified as 'contested', as there is a lack of clarity and consensus about the aetiology and manifestations of the illness that render it insecurely positioned in medical and social discourse (Madden \& Sim 2016). A person with fibromyalgia, their practitioners, institutions, workplaces and social networks are continuously challenged to prove the existence of the condition as a serious and chronic illness (McMahon et al. 2012, Chen 2015). This 
paper aims to assess the impact of contestation related to fibromyalgia as a diagnosis on an individual's ability to articulate their experience to family and support networks.

This aim relates to the theoretical understanding that fibromyalgia is a complex condition that relies heavily on the patient's telling of symptoms and practitioners' compliance and collaboration in taking the illness seriously (Frank 1997, Durif-Bruckert et al. 2015, Price \& Walker 2015). In many instances, practitioners often tell people diagnosed with fibromyalgia that treatment is not available. Therefore, the process of coping with symptoms, their unpredictable onset and multiple expressions is experienced externally to clinical intervention (Frank 2010). Within this theoretical context, this paper focuses on the spaces where people with fibromyalgia make sense of their illness and the resources they draw on in this process, namely medical knowledge, family, partners and peers. In doing so, the paper aims to gauge the role of social support in the individual's illness experience of fibromyalgia.

Govender (2004) estimates that the prevalence of fibromyalgia in South Africa (SA) is around 3\% in the general population. A core component of contextually understanding fibromyalgia in SA is the impact of the availability and provision of medical insurance in accessing healthcare and treatment (Ibanez-Gonzalez \& Greenstein 2014). The inequities found in healthcare provision (Eyles et al. 2015) determine the ability of a person diagnosed with fibromyalgia in SA to act as a healthcare consumer. Namane (2013, p. 380) explains that 'most primary healthcare (PHC) workers are not skilled in the diagnosis and management of musculoskeletal conditions, although they amount to $15 \%$ of a general practitioner's workload' in SA. Rauf et al. (2013) assert that there is very little information available concerning chronic pain prevalence in SA PHC settings. This negligence occurs despite the profound biopsychosocial impact of chronic pain on the quality of life for the individual, and 'significant impact on the utilisation of healthcare services' found in addressing these conditions (Rauf et al. 2013, p. 85). This paper shows that the management of fibromyalgia is shaped by differential access to resources, due to the divisions between public and private healthcare that is characteristic of SA (Mclntyre et al. 2007, Stuckler et al. 2011), and impinge on this process.

In $\mathrm{SA}$, the broader environment surrounding people diagnosed with fibromyalgia is especially important to consider, given the impact of the variations in patient access to care which reflects socioeconomic boundaries (Chetty et al. 2012). Fibromyalgia as an illness experience requires understanding and action, from the person at the centre of the experience, and those who surround and support this individual (McMahon et al. 2012). While there is a growing South African body of literature related to the subject, most studies are concerned with clinical aspects, such as chronic pain diagnosis and treatment (Namane 2013, Raff et al. 2014). The perspective of the patient in this literature is almost entirely absent (Walker \& Esterhuyse 2013, Fried et al. 2015). Therefore, this paper aims to explore the role of social support in addressing the various challenges presented by the complexity of fibromyalgia in this context, through a discussion of the narratives of people living with fibromyalgia.

\section{Methods}


This paper reports the findings of a qualitative study that used in-depth interviews in collecting data. The aim was to illuminate the specific experiences and navigating tools utilised by people living with fibromyalgia in SA (Weiss 1995, De Vaus 2001, Fried et al. 2015).

An illness narrative is a critical way for people to make sense of and accept fibromyalgia in their lives (Frank 1997, Dennis et al. 2013). Narratives are therefore a necessary and useful method for gaining insight into people's accounts of a complex, often hidden illness experience (Kleinman 1988, Keikelame \& Swartz 2013). In drawing out data through this approach, thematic content analysis was employed to interpret the findings following a framework defined by the central concerns of the study (Lee \& Poole 2005).

This study contains elements of both the content of the narratives, as well as how they were able to emerge (Kleinman 1988, Stanley 2008, Sools 2013). The study did not aim to present a generalizable perspective of fibromyalgia, and rather sought to provide a nuanced understanding of the experiences of a select group of people living with the condition by exploring their narratives (Nettleton 2006, Barbour 2008). Using individual cases and finding narrative threads that could connect participants as a community was important, especially in understanding the role of social support in coping with this illness experience (Fried et al. 2015). Analysing these narratives in the South African context goes further than many other studies based in this environment (Keikelame \& Swartz 2013).

\section{Study sample}

Seeking participants was a process of connecting the researcher through informal peer networks, and it was important to build trust and rapport with those people who were willing to discuss their experience. Participants were drawn into the study by employing snowball sampling, which was purposive in approach (Barbour 2008). The sampling method was useful and suitable for this study, as people who joined were part of the broader social network of the researcher. Contacting people with the condition through their peers, families and practitioners meant that there was personal connection and sufficient time to ensure the participants were fully informed before taking part in the study (Barbour 2008). The research follows the approach of Weiss (1995, p. 137) as the researcher was both embedded within and apart from 'the milieu in which the respondents live'.

The researcher contacted 20 people, and 15 were subsequently interviewed. Thirteen of the participants had received a formal diagnosis of fibromyalgia. Two had self-diagnosed with fibromyalgia by searching the Internet and through the lay referral system (Sharf 2006, Tang \& Ng 2006). The latter were included in the study because of the way in which their narratives fitted within the complex picture that emerged during the course of the research process. The participants were all women aged between 23 and 59. Diagnosis occurred in private healthcare settings. This further reflects the quantity of resources (fiscal and personal) required to pursue the diagnosis of fibromyalgia, and then to continue attempting to live with the condition (McIntyre et al. 2003, Eyles et al. 2015). Fourteen of the women were South African and one had a British background. Thirteen were white people, and 
two were coloured women ${ }^{1}$. Thirteen were English-speaking, two were Afrikaans-speaking. Medical insurance access was uneven among the sample, as older participants generally had good access to medical care, while younger participants were financially insecure and as a result had minimal or no access. Medical insurance access was seen as a determining factor in attaining diagnosis and shaped the management of fibromyalgia for the participants in this study. Table 1 offers further details of the demographic background of the participants.

Table 1. Participant demographics

\begin{tabular}{|c|c|c|c|c|c|}
\hline Name & Age & Occupation & $\begin{array}{l}\text { Years since } \\
\text { diagnosis }\end{array}$ & Marital status & $\begin{array}{ll}\text { Area } \\
\text { residence }\end{array}$ \\
\hline Alison & 23 & Student & 3 & Single & Johannesburg \\
\hline Beth & 57 & $\begin{array}{l}\text { Programme } \\
\text { Manager }\end{array}$ & $\begin{array}{l}\text { Self- } \\
\text { diagnosed }\end{array}$ & Married & Johannesburg \\
\hline Chloe & 23 & $\begin{array}{l}\text { Freelance } \\
\text { Writer }\end{array}$ & 5 & Single & Johannesburg \\
\hline Claire & 37 & Psychologist & 2 & Divorced & Johannesburg \\
\hline Connie & 39 & $\begin{array}{l}\text { Human } \\
\text { Resources } \\
\text { Director } \\
\end{array}$ & 10 & Married & Johannesburg \\
\hline Frances & 59 & $\begin{array}{l}\text { Veterinary } \\
\text { Nurse }\end{array}$ & 18 & Married & Pietermaritzburg \\
\hline Helena & 49 & Consultant & 6 & Single & Johannesburg \\
\hline Jenna & 27 & $\begin{array}{l}\text { Freelance } \\
\text { Writer }\end{array}$ & $\begin{array}{l}\text { Self- } \\
\text { diagnosed }\end{array}$ & Single & Durban \\
\hline Karen & 24 & $\begin{array}{l}\text { University } \\
\text { Lecturer }\end{array}$ & 2 & Single & Pretoria \\
\hline Kate & 31 & $\begin{array}{l}\text { Swimming } \\
\text { Instructor }\end{array}$ & 10 & Married & Johannesburg \\
\hline Michelle & 51 & $\begin{array}{l}\text { Programme } \\
\text { Manager }\end{array}$ & 7 & Married & Johannesburg \\
\hline Rebecca & 32 & $\begin{array}{l}\text { Swimming } \\
\text { Instructor }\end{array}$ & 4 & Single & Johannesburg \\
\hline Shreela & 48 & $\begin{array}{l}\text { University } \\
\text { Lecturer }\end{array}$ & 9 & Divorced & Johannesburg \\
\hline Teresa & 25 & Student & 7 & Single & Pietermaritzburg \\
\hline Zainab & 51 & $\begin{array}{l}\text { Administration } \\
\text { Manager }\end{array}$ & 20 & Divorced & Johannesburg \\
\hline
\end{tabular}

It is acknowledged that due to the complex context, the study sample is not representative of the demographics of SA, as the participants were all educated, middle-class women, and living in urban and residential areas of SA. Having said this, it is an important reflection of illnesses that require

\footnotetext{
${ }^{1}$ The use of the terms 'African', 'Coloured', 'Indian' and 'White' reflects a statutory stratification of the South African population in terms of the former Population Registration Act. The use of these terms does not imply the legitimacy of this racist terminology. It is a necessary component to acknowledge the diversity of South African society and is used to describe groupings that previously had differential access to services, economic opportunity, education and healthcare, among other resources. It is done to highlight the impact of former apartheid policies on various South African systems (Mclntyre et al. 2007, p. 10; Wadee et al. 2003, p. 4)
} 
pursuit and high interaction with healthcare providers and practitioners (such as medical insurance, private healthcare facilities and specialist doctors) to attain the diagnosis (Arnold et al. 2012). This study, through the sample dynamics, is reflective of the broader trends of fibromyalgia as a gendered phenomenon, with women disproportionately represented in the experience of the condition (Barker 2011).

The opportunity to speak to people living with a chronic condition was a matter of timing (Thomas \& Johnson 2000). The five people who declined to participate gave varied reasons for this decision. These included the perception that their experience with fibromyalgia had passed, and that they had no desire to revisit what was a challenging and upsetting part of their life. Others felt that their symptoms were currently too overwhelming to reflect on and articulate the experience coherently. It was therefore apparent that opportunities to speak about illness experience aligned with the stage of the participant's condition, and shaped the willingness of individuals to either accept or decline participation in the study (Barbour 2008, Mik-Meyer \& Obling 2012).

\section{Data collection}

Data collection occurred between August 2012 and February 2013. Semi-structured face-to-face interviews were used, and a conversational tone was adopted in order to encourage the natural development of a participant's 'small story' (Sools 2013), which is characteristic of narrative approach. The interview was loosely structured as participants were encouraged to talk openly and freely, often straying from the central topics of the study (Nettleton 2006, Barbour 2008). In telling stories from their lives, participants also related the key events that characterised their experiences before, after and during their encounters with fibromyalgia and other illnesses (Whitehead 2006). The interviews lasted between one and three hours in duration, were recorded with the consent of participants, and conducted in English.

Data analysis

Once the interviews had been conducted and transcribed by the researcher, in-depth thematic analysis occurred. The sheer quantity of data that emerged from this research process ensured that data saturation was reached within the interviews. QSR Nvivo 10 was used to manage and partially analyse the data along a broad coding frame (Price \& Walker 2014). The analysis is thematically organised in this paper, in order to identify and explore the particular issues that emerged across the narratives (Lee \& Poole 2005). These include social support, family and partner relationships, and peer support. The data produced through this study also required the use of narrative analysis techniques, which was useful in explaining the perceptions, feelings, experiences and interactions of people living with fibromyalgia in a SA context (Luttrell 2005). 
The Ethics Committee of the University of the Witwatersrand granted ethics clearance in 2012. The paper employs pseudonyms throughout to maintain anonymity. The study utilised informed and voluntary consent in drawing participants into the research process. Each participant was given a detailed information sheet, and briefed fully on the purpose and nature of the research. Reflexivity on the part of the researcher was crucial in assessing the extent to which participants were comfortable and able to relate their experiences, without being affected, both by the process and because of their condition (Nettleton 2006). Much care and flexibility was needed in conducting this research. As the participants were people who live with a condition that includes exhaustion as a symptom, their wellbeing had to be held as paramount in this process. Wassenaar (2006, p. 63) explains that, 'participants' dignity and welfare should always transcend the interest of the research'.

The main limitation of this research remains the inability to generalise beyond the sample of the study. The study reported on in this paper has low external validity, as the findings cannot be seen to be generally relevant or extrapolated outside of the sample population. Having said this, there are many components of the research process that were very successful, and are highly replicable as a research approach and design. Additionally, the data garnered through this process was rich, detailed and revelatory of processes, experiences and interactions that are important to acknowledge (Bleakley 2005, Barbour 2008, Timmermans 2013).

\section{Findings}

Integrating literature, theory and data, the findings of the study are presented and analysed in this section. Using the themes of social support, family and partner relationships, peer support, a specific application of patient-experience-explanations of the role of social support in fibromyalgia in SA is discussed.

\section{Social support in shaping fibromyalgia experience}

Many things, such as noise, light and smell, can trigger symptoms of fibromyalgia. The fluctuations in the appearance and disappearance of symptoms presented additional opportunities for scepticism to be generated from the people surrounding the individual with fibromyalgia (Dennis et al. 2013). Shreela explained the difficulties faced in getting support in attempting to accommodate her condition when it was still relatively overwhelming. Shreela described how:

People get impatient with you. Because ... [They say] 'Well you were walking last week ... you know ... how come you can't get out of bed today?' Uh ... you constantly have to explain ... They kind of [say] ... 'Well what is that?' when you say, 'I was diagnosed with fibromyalgia...' Generally, social insensitivity, and not only to fibromyalgia ... prevents me from sharing it with just anybody.

Shreela had experienced a lack of accommodation, as people in her social environment could not comprehend the all-encompassing and variant nature of her fibromyalgia (Sahar et al. 2016). Consequently, Shreela was unwilling to open herself up to scepticism from others, and so declined 
disclosing her diagnosis to people she did not trust (Gilson 2003, Scrambler 2009). She placed importance and dependence on people she felt would be understanding and supportive, rather than those who had previously treated herself and her condition with disbelief (Skuladottir \& Halldorsdottir 2011).

Family support

Family plays an indispensable role in forming perceptions and health behaviours when approaching and coping with fibromyalgia. Social capital granted through familial systems provides access to knowledge and resources that enhance health (Rodham et al. 2010, Marcus et al. 2013). Support from Kate's parents throughout her encounter with fibromyalgia had an enormous impact on her experiences. Her symptoms had been severe and disabling, and so her parents intervened by taking her to a healthcare practitioner, who had immediately been able to recognise and categorise her experience (Rodham et al. 2010). She explained that:

My mom, my parents were a big motivator - and they said, 'Look, you can either just lie down and take it and be sick and sorry for yourself and not do anything with your life ... or you can fight it'. And thank goodness, because you do need that motivation.

Kate's parents gave her illness credence, and encouraged her to do everything possible to get better. Kate was able to tackle her experience of fibromyalgia in a supportive environment, and eventually she recovered (Bendelow 2009).

Like Kate, Alison could attribute the positive attitude she held in relation to her health to her mother. Alison noted that:

Whatever comes [my mom's] way; she just deals with it and then moves on. And I think that has helped me because whenever anything came up around in my life then I'd just be like, 'ok I'm going to deal with it now, finish, and then move on'.

Alison explained that interacting with her father around her illness was tougher, as he had a different opinion of the condition from her mother. Alison's father had previously paid for medical insurance, which also strained their relationship when dealing with her fibromyalgia (Rodham et al. 2010, Issner et al. 2012, Eyles et al. 2015). She explained that:

I still don't think [my dad] was ... really understood what [fibromyalgia] was, or that he ... really believed it's what it was but ... like, he knows [now]. And ... now that I'm on my [own] medical aid like ... he doesn't really have a say any more about how much I spend and things like that. So I think that also had an impact.

Alison had to convince her father repeatedly that her illness had medical recognition. The range of symptoms linked to her condition complicated this process of legitimation (Barker 2011). Her 
fibromyalgia was an underlying component of her illness experience as she also had chronic sinusitis, migraines and irritable bowel syndrome. This led to high healthcare utilisation with frequent visits to the doctor, as well as an inability to explain the totality and connections between her conditions (Sauer et al. 2011, Dennis et al. 2013, Marcus et al. 2013, Sahar et al. 2016).

Most of the younger participants had had trouble engaging with their parents around the unpredictable and chronic nature of their symptoms. Participants were also particularly baffled when parents who also had chronic conditions themselves were perceived to be unsupportive and unhelpful (Bogenschneider \& Pallock 2008, López-Martínez et al. 2008). Chloe's mother lived with arthritis, and given the overlapping symptomatology of that condition and fibromyalgia, she found it puzzling that her mother was unable to be sympathetic to her plight. Chloe's family was generally derisive about her fibromyalgia, because they misinterpreted the meanings of her conditions, cast her as 'always sick' and almost wilfully unable to get better (Timmermans \& Almeling 2009, Campbell et al. 2011). She noted that her mother responded to her with:

Almost aggression ... I guess it's like a [maternal] thing; if your children are not doing well in one thing you can either be super sympathetic or you can react to it ... um, out of anger because there's that protective thing. I don't understand it, I really don't. JA ${ }^{2}$, she seems to get angry with me when I'm in pain or ... like super tired.

Part of familial support for chronic illness, and the difficulties faced in drawing on it effectively, lies in the inability of families to offer advice and treatments that could alleviate symptoms (Lupton 2003). As evidenced here, participants also experienced feelings of despair, rejection and dejection, specifically when people were unsympathetic to the nature and severity of their fibromyalgia experience (Scrambler 2009, Price \& Walker 2015).

\section{Family support and medical insurance}

Karen accessed medical insurance with the assistance of her parents, and Frances' medical insurance was provided by her husband's workplace. In the latter instance, Frances was able to draw on resources and access to a comprehensive and generous medical insurance through her husband's position and workplace, which in turn showed how her social capital afforded her access to better healthcare (Giordano \& Lindstrom 2010). She did contextualise her experience of interacting with medical insurance providers around her fibromyalgia by the fact that her treatment largely occurred in the mid-1990s, before the advent of highly complicated, bureaucratised medical categorisation and privatisation of healthcare in SA (Gilson 2003, Mclntyre et al. 2007).

The converse occurs when a lack of family resources means the individual is left without medical insurance, and therefore has to alter the way in which they interact with healthcare providers, because frequent consultation and treatments prescribed are prohibitively costly. This was the case for Chloe, Jenna and Teresa, all of whom were young and infrequently employed, and therefore still

2 'Ja' is Afrikaans for 'yes' and is commonplace in South African speech. 
highly dependent on their families for fiscal support and practical care in managing their fibromyalgia. The differences in availability of medical insurance reflected what Percheski and Bzostek (2013) asserted in terms of familial access and healthcare utilisation. Over and above providing care and support to someone living with a chronic condition, families also absorbed the financial burden, either by supplementing medical expenditure of their dependants through insurance, or by making out-ofpocket payments for necessary consultations and treatments (Eyles et al. 2015).

Teresa related an incident when she was very ill, and as a young student living away from home, she was not in an optimally supportive environment. She went on to describe how:

The girl who lived in the next room to me called the doctor, made an appointment for me ... I went there and the doctor said that I actually had severe bronchitis and she wanted to send me to hospital because she said it was probably going to turn into pneumonia. I was like, 'please don't take me to hospital'. And I was like, 'I also can't afford to go to hospital'.

Her family did not have medical insurance, and therefore, they struggled to pay for consultation and treatment costs outside of preferential medical insurance rates (Percheski \& Bzostek 2013). Teresa's lack of medical insurance shaped her approach to her health, and as she felt unsupported and misunderstood, she (as well as other participants) felt driven to push harder against the limits of the condition, and this often resulted in worsened symptoms (Aujoulat et al. 2008).

\section{Social support from partners}

In this context of low levels of familial support, most participants turned to partners who were assistive in confronting the unpredictable and elusive nature of fibromyalgia. By presenting information, referrals to practitioners, and emotional support for the person living with the condition, partners were instrumental in fostering the individual's capacity to cope with a confusing and challenging illness experience (Campbell et al. 2011). Partners provided practical care, and afforded empathy for the experience as it manifested, rather than how illness is expected to unfold, and allowed them to be 'sick' (Oliver et al. 2001). Providing support in this way was empowering for those with the condition, and receiving care and empathy from partners had a particularly profound impact on facilitating a return to health for the person with fibromyalgia (Kool et al. 2009, Price \& Walker 2015).

There were partners of participants who were able to offer tailored social support that met their needs, and allowed them to move through their illness experience with fibromyalgia in relative comfort. For instance, Claire (who was divorced) felt supported by her new partner, as he did not question the vague nature of the diagnosis, or the unpredictability of the symptoms she experienced. She explained that:

I think it feels hard to ... to allow myself that and it also feels hard that other people would just accept it. My boyfriend and I had slept in late [one Sunday] and then he went off to go do 
some stuff and then I sent him a message ... [Saying] 'I just had this really disastrous day; I just slept all day'. And he said, 'Well that's great. You know, you needed the rest'. In my head, [I'm] thinking, "he must just think that like I'm a total ... kind of ... "lazy" is the word that comes to mind ... I'm just like a bit of a slacker', you know.

In encountering her new partner's attitude of acceptance of her condition, Claire was able to begin to view her illness in a different light, and therefore, she was also able to eventually shift her perception of rest as necessary, rather than as a sign of 'laziness' or 'slacking' (Jackson 2005).

Conversely, when partners were perceived as being derisive and unsupportive of the person with fibromyalgia, there was damage done to the ability of the individual to embody an illness identity, which would have enabled them to manage the condition effectively. Connie's husband exemplified the negative aspects of relating with partners around fibromyalgia. He persistently doubted the severity of Connie's illness, and could not accept the multiplicity of the condition and therefore struggled to support her. Connie was reluctant to give in to her symptoms until she literally collapsed, and as a result, she found it difficult to adhere to the notion of resting as part of her treatment (Morris et al. 2012).

\section{Peer support networks}

Claire, Connie, Karen and Helena had all been referred by people in their social networks to specialists in attaining their diagnosis. Their peers were all people who knew about fibromyalgia or had the condition themselves.

Claire's experience led her to turn initially to other sources of information and counsel, rather than medical practitioners (Barker 2008). Her narrative highlighted the role of peer support and selfdiagnosis in coming to the label of fibromyalgia (Gage 2013), and subsequently, she (like other participants) became an important source of social support for others living with the condition (Skuladottir \& Halldorsdottir 2011, Mazanderani et al. 2012, Chen 2015).

Another participant, Zainab, explained how she had given advice to a colleague and a friend when they had each been diagnosed with fibromyalgia. She was at a point in her illness career that allowed her to feel emotional distance from the meanings of the condition. She was also able to contextualise the condition, having realised the chronicity of the experience and the strategies that had worked for her. This process was not without complication, however, as Zainab was unsure that her advice was matched to her friend's specific manifestation of pain. She explained that:

Well its ... it's like [a] swim or sink kind of thing ... I think if people are pushed, because even with my friend ... although she claims ... how debilitating it is and everything ... but when she needs to do something then she can do it. You know, it's not like she can't ... and that's also what I found is ... even ... like, you think, 'oh well ... I'm so sick I can't lift this thing', but you go and lift the thing up, and nothing happens to you, you know? So you ... it's more [about] not 
being afraid ... you see, that's where I'm also a bit worried, is that sometimes ... I'm saying 'maybe this is me, maybe this is what my condition is, where I can do all that' ... but sometimes I say it to, like even my friend, I said 'you know what, I promise you, if you go and lift something heavy, nothing's going to happen to you. If you do it the right way, nothing's going to happen to you' ... exactly like the next person ... if you do it the wrong way, lift something the wrong way and you know you might hurt [yourself] ... It's because ... ja ... it's that ... imbalance or whatever it is ... ja ... but then afterwards I think, you know am I giving the right [advice]? ... Maybe ... her pain is different.

Frances also shared her thoughts on strategies for successfully living with fibromyalgia, which she willingly offered to other people who were also going through the experience. She felt it was important to have good rapport with their practitioner and that the individual should be an active patient in the encounter (Arnold et al. 2012). She explained that:

In acceptance, you have to stop fighting with yourself over it. I think you have to find ways to keep yourself busy. Because there's nothing worse than sitting and thinking about it ... And ... you have to be positive about it. You have to know that, 'yip, ok, your body's let you down', but there's a lot more you can do around that. You have to talk about it. You have to be open about it, it's a problem but it's [just] a problem ... And if it takes medication to help you deal with it, so you will [take medication]. There's no stigma in taking an antidepressant if it ... helps you sleep at night, because if you can sleep at night, you can deal with pain during the day.

In this study, consistent with others, the normalisation of symptoms, behaviours and attitudes to treatments proved to be an important aspect of coping with fibromyalgia, and of being able to offer and draw social support to and from others (Campbell et al. 2011, Gage 2013).

\section{Discussion and conclusion}

Familial support was shown to contribute to the capacity of the individual with fibromyalgia to make sense of their experience, and respond to it appropriately. This occurs in a variety of ways; by offering information and advice, recognising symptoms as problematic, ensuring medication is taken appropriately, and alleviating the sick individual from domestic and other obligations (Cedraschi et al. 2012, Price \& Walker 2015). The narratives explored in this study confirm that social capital through familial relationships shapes fibromyalgia experience and health outcomes.

The South African context proved to be a pertinent factor in the experiences of the people interviewed for this study. Familial and partner support in accessing healthcare through medical insurance and other financial resources was a salient issue for the study population (Eyles et al. 2015). The participants recognised the integral effect that their supportive family members and partners had on their experience of fibromyalgia. Care from family and partners was indispensable in managing the condition, both in ensuring access to treatment, as well as alleviation from family and household duties. After the event of the diagnosis, the family has an important role to play in the ongoing process of making sense of the label of fibromyalgia and coping with the condition, as revealed by the findings of this study, which confirmed the existing literature (Giordano \& Lindstrom 2010, Rodham et al. 2010, Percheski \& Bzostek 2013). 
An additional dimension, highlighted here, was the ways in which people with fibromyalgia provide support to others with the condition. As discussed by Gage (2013), a clear practice emerged in the study whereby those who had had the condition for a number of years and were mostly managing their fibromyalgia, were able and willing to give information, advice and support to those who had recently acquired the diagnosis. The participants were able to draw on support and resources from their social network, in order to find a practitioner who could recognise and respond to their inexplicable symptoms (Oliver et al. 2001, Campbell et al. 2011). Although exploratory in nature, this study offers a nuanced understanding of the role of social support in the experience of fibromyalgia in SA, and has the potential to stimulate further research on this topic.

\section{Acknowledgements}

The authors acknowledge the invaluable contribution of the participants of this study, and thank them for their generosity, perspectives and insight.

\section{Funding}

This work was supported by the University of the Witwatersrand, the National Research Foundation and the Andrew W. Mellon Foundation.

\section{References}

Arnold L.M., Clauw D.J., Dunegan L.J. \& Turk D.C. (2012) A framework for fibromyalgia management for primary care providers. Mayo Clinic Proceedings 87 (5), 488-496.

Aujoulat I., Marcolongo R., Bonadiman L. \& Deccache A. (2008) Reconsidering patient empowerment in chronic illness: a critique of models of self-efficacy and bodily control. Social Science \& Medicine 66, 1228-1239.

Barbour R. (2008) Introducing Qualitative Research: A Student's Guide to the Craft of Doing Qualitative Research. SAGE, London.

Barker K.K. (2008) Electronic support groups, patient-consumers, and medicalization: the case of contested illness. Journal of Health and Social Behavior 49 (1), 20-36.

Barker K.K. (2011) Listening to Lyrica: contested illnesses and pharmaceutical determinism. Social Science \& Medicine 73 (6), 833-842.

Bendelow G. (2009) Beyond biomedicalisation: integrated models of health and illness. Health, Emotion and the Body, Polity Press, Cambridge.

Bleakley A. (2005) Stories as data, data as stories: making sense of narrative inquiry in clinical education. Medical Education 39 (5), 534-540.

Bogenschneider K. \& Pallock L. (2008) Responsiveness in parent-adolescent relationships: are influences conditional? Does the reporter matter? Journal of Marriage and Family 70 (4), 1015-1029.

Campbell P., Wynne-Jones G. \& Dunn K.M. (2011) The influence of informal social support on risk and prognosis in spinal pain: a systematic review. European Journal of Pain 15, 5, 444.e1-444.e14. 
Cedraschi C., Luthy C., Girard E., Piguet V., Desmeules J. \& Allaz A.-F. (2012) Representations of symptom history in women with fibromyalgia vs. chronic low back pain: a qualitative study. Pain Medicine 13, 1562-1570.

Chen A.T. (2015) Information use and illness representations: understanding their connection in illness coping. Journal of the Association for Information Science and Technology 66 (2), 340-353.

Chetty S., Baalbergen E., Bhigjee A.I. et al. (2012) Clinical practice guidelines for management of neuropathic pain: expert panel recommendations for South Africa. South African Medical Journal 102 (5), 312-325.

De Vaus D. (2001) Research Design in Social Research, pp. 1-52. Sage Publications, Thousand Oaks, California.

Dennis N.L., Larkin M. \& Derbyshire S.W.G. (2013) "A giant mess" - making sense of complexity in the accounts of people with fibromyalgia. British Journal of Health Psychology 18 (4), 763-781.

Durif-Bruckert C., Roux P. \& Rousset H. (2015) Medication and the patient-doctor relationship: a qualitative study with patients suffering from fibromyalgia. Health Expectations 18 (6), 2584-2594.

Eyles J., Harris B., Fried J., Govender V. \& Munyewende P. (2015) Endurance, resistance and resilience in the South African health care system: case studies to demonstrate mechanisms of coping within a constrained system. BMC Health Services Research 15, 432.

Frank A.W. (1997) The Wounded Storyteller, Body, Illness and Ethics. University of Chicago Press, Chicago.

Frank A.W. (2010) Letting Stories Breathe: A Socio-Narratology. University of Chicago Press, Chicago.

Fried J., Harris B., Eyles J. \& Moshabela M. (2015) Acceptable care? Illness constructions, healthworlds, and accessible chronic treatment in South Africa. Qualitative Health Research 25 (2), 622-635.

Gage E.A. (2013) Social networks of experientially similar others: formation, activation, and consequences of network ties on the health care experience. Social Sciences \& Medicine 95, 43-51.

Gilson L. (2003) Trust and the development of health care as a social institution. Social Science \& Medicine 56 (7), 1453-1468.

Giordano G.N. \& Lindstrom M. (2010) The impact of changes in different aspects of social capital and material conditions on self-rated health over time: a longitudinal cohort study. Social Science \& Medicine 70, 700-710.

Govender C.O. (2004) The Psychological Profiles of Fibromyalgia Patients: Towards a Model of Taxonomy and Maintenance of the Illness. MA Thesis. University of Pretoria. Available at: http://upetd.up.ac.za/thesis/available/etd-03062006-095005/ (accessed on 21/01/2016).

Ibanez-Gonzalez D.L. \& Greenstein R. (2014) Chronic illness and the urban healthworld: a Sowetan case study. South African Review of Sociology 45, 97-116.

Issner J.B., Cano A., Leonard M.T. \& Williams A.M. (2012) How do I empathize with you? Let me count the ways: relations between facets of pain-related empathy. The Journal of Pain 13, 167-175.

Jackson J.E. (2005) Stigma, liminality, and chronic pain: mind-body borderlands. American Ethnologist $32(3), 332-353$. 
Keikelame M.J. \& Swartz L. (2013) A lay carer's story about epilepsy in an urban South African context: they call it an illness of falling or an illness of fitting because a person shakes and eventually falls. Epilepsy \& Behavior 28 (3), 512-518.

Kleinman A. (1988) The Illness Narratives: Suffering, Healing, and the Human Condition. Basic Books, New York.

Kool M.B., van Middendorp H., Boeije H.R. \& Geenen R. (2009) Understanding the lack of understanding: invalidation from the perspective of the patient with fibromyalgia. Arthritis \& Rheumatism 61, 1650-1656.

Lee A.M. \& Poole G. (2005) An application of the transactional model to the analysis of chronic illness narratives. Qualitative Health Research 15 (3), 346-364.

López-Martínez A.E., Esteve-Zarazaga R. \& Ramírez-Maestre C. (2008) Perceived social support and coping responses are independent variables explaining pain adjustment among chronic pain patients. The Journal of Pain 9 (4), 373-379.

Lupton D. (2003) Medicine as Culture. SAGE, London.

Luttrell W. (2005) "Good enough" methods for life-story analysis: chapter 7. In: N. Quinn (Ed.) Finding Culture in Talk: A Collection of Methods, pp. 243-268. Palgrave Macmillan, New York.

Madden S. \& Sim J. (2016) Acquiring a diagnosis of fibromyalgia syndrome: the sociology of diagnosis. Social Theory \& Health 14 (1), 88-108.

Marcus D.A., Richards K.L., Chambers J.F. \& Bhowmick A. (2013) Fibromyalgia family and relationship impact exploratory survey. Musculoskeletal Care 11, 125-134.

Mazanderani F., Locock L. \& Powell J. (2012) Being differently the same: the mediation of identity tensions in the sharing of illness experiences. Social Science \& Medicine 74, 546-553.

McIntyre D.I., Doherty J. \& Gilson L. (2003) A tale of two visions: the changing fortunes of social health insurance in South Africa. Health Policy and Planning 18, 47-58.

McIntyre D., Thiede M., Nkosi M., Mutyambizi V., Castillo-Riquelme M., Goudge J., Gilson L. \& Erasmus E. (2007) A Critical Analysis of the Current South African Health System. University of Cape Town: Health Economics Unit, University of the Witwatersrand: Centre for Health Policy.

McMahon L., Murray C., Sanderson J. \& Daiches A. (2012) "Governed by the pain": narratives of fibromyalgia. Disability and Rehabilitation 34, 1358-1366.

Mik-Meyer N. \& Obling A.R. (2012) The negotiation of the sick role: general practitioners' classification of patients with medically unexplained symptoms. Sociology of Health \& Illness 34 (7), 1025-1038.

Morris L., Grimmer-Somers K.A., Louw Q.A. \& Sullivan M.J. (2012) Cross-Cultural Adaptation and Validation of the South African Pain Catastrophizing Scale (SA-PCS) among Patients with Fibromyalgia Health and Quality of Life Outcomes 10, 137.

Namane M.K. (2013) Consultation outcomes for musculoskeletal conditions at two community health centres in Cape Town. South African Family Practice 55 (4), 380-384.

Nettleton S. (2006) The Sociology of Health and Illness. Polity, Cambridge. 
Oliver K., Cronan T.A., Walen H.R. \& Tomita M. (2001) Effects of social support and education on health care costs for patients with fibromyalgia. Journal of Rheumatology 28 (12), 2711-2719.

Percheski C. \& Bzostek S. (2013) Health insurance coverage within sibships: prevalence of mixed coverage and associations with health care utilization. Social Science \& Medicine 90 (August), 1-10.

Price E. \& Walker E. (2014) Diagnostic vertigo: the journey to diagnosis in systemic lupus erythematosus. Health (London) 18 (3), 223-239.

Price L. \& Walker L. (2015) Chronic Illness, Vulnerability and Social Work: Auto-Immunity and the Contemporary Disease Experience. Routledge, London.

Raff M., Crosier J., Eppel S., Meyer H., Sarembock B. \& Webb D. (2014) South African guideline for the use of chronic opioid therapy for chronic non-cancer pain. South African Medical Journal 104 (1), 7989.

Rauf W.-N., Meyer H.P., Marcus T.S. \& Becker P.J. (2013) Prevalence of chronic pain in patients attending primary healthcare facilities in south-west Tshwane. South African Family Practice 55 (1), $85-89$.

Rodham K., Rance N. \& Blake D. (2010) A qualitative exploration of carers' and "patients" experiences of fibromyalgia: one illness, different perspectives. Musculoskeletal Care 8, 68-77.

Sahar K., Thomas S.A. \& Clarke S.P. (2016) Adjustment to fibromyalgia: the role of domain-specific selfefficacy and acceptance. Australian Journal of Psychology 68 (1), 29-37.

Sauer K., Kemper C. \& Glaeske G. (2011) Fibromyalgia syndrome: prevalence, pharmacological and non-pharmacological interventions in outpatient health care. An analysis of statutory health insurance data. Joint Bone Spine 78, 80-84.

Scrambler G. (2009) Health related stigma. Sociology of Health \& IIIness 31, 441-455.

Sharf B.F. (2006) How I fired my surgeon and embraced and alternative narrative. In: L.M. Harter, P.M. Japp \& C.S. Beck (Eds) Narratives, Health, and Healing: Communication Theory, Research, and Practice, pp. 325-342. Routledge, Mahwah, New Jersey.

Skuladottir H. \& Halldorsdottir S. (2011) The quest for well-being: self-identified needs of women in chronic pain. Scandinavian Journal of Caring Sciences 25 (1), 81-91.

Sools A. (2013) Narrative health research: exploring big and small stories as analytical tools. Health (London) 17 (1), 93-110.

Stanley L. (2008) Madness to the method? Using a narrative methodology to analyse large-scale complex social phenomena. Qualitative Research 8, 435-447.

Stuckler D., Basu S. \& McKee M. (2011) Health care capacity and allocations among South Africa's provinces: infrastructure-inequality traps after the end of Apartheid. American Journal of Public Health 101 (1), 165-172.

Tang H. \& Ng J.H.K. (2006) Googling for a diagnosis-use of Google as a diagnostic aid: internet based study. BMJ 333, 1143-1145.

Thomas S.P. \& Johnson M. (2000) A phenomenologic study of chronic pain. Western Journal of Nursing Research 22, 683-705. 
Timmermans S. (2013) Seven warrants for qualitative health sociology. Social Science \& Medicine 77, $1-8$.

Timmermans S. \& Almeling R. (2009) Objectification, standardization, and commodification in health care: a conceptual readjustment. Social Science \& Medicine 69 (1), 21-27.

Wadee H., Gilson L., Thiede M., Okorafor O. \& McIntyre D. (2003) Health Care Inequity in South Africa and the Public/Private Mix. University of Geneva (UNIGE), Geneva.

Walker S.P. \& Esterhuyse K.G.F. (2013) Pain severity, coping and satisfaction with life in patients with chronic pain. Southern African Journal of Anaesthesia and Analgesia 19, 252-256.

Wassenaar D. (2006) Ethical issues in social science research. In: M. Terre Blanche, K. Durrheim \& D. Painter (Eds) Research in Practice: Applied Methods for the Social Sciences, pp. 60-79. UCT Press, Cape Town.

Weiss R. (1995) Learning from Strangers: The Art and Method of Qualitative Interview Studies. Free Press, New York.

Whitehead L.C. (2006) Quest, chaos and restitution: living with chronic fatigue syndrome/myalgic encephalomyelitis. Social Science \& Medicine 62 (9), 2236-2245. 